\title{
Experimental Investigation of Various Shell Footings in Cohesive and Cohesionless Soil
}

\author{
M. Kumar a, , M. Subagiriraj a \\ a Department of Civil Engineering, Government College of Technology, Coimbatore, Tamil Nadu, India.
}

${ }^{*}$ Corresponding Author

kumargeo_77@gct.ac.in

(M. Kumar)

Received : 20 04 2019

Accepted : 19 05 2019

\begin{abstract}
The increasing demand of infrastructure development leads to the usage of sandy soils; which possess low bearing capacity. In this regard, this study is to provide a novel solution to counteract the problems faced by the weak soil. The experimental study was carried out on both Flat and Shell models with the corresponding Triangular, Square and Hexagon shapes for both loose and medium dense condition. The models were compared based on their equal plan area. To carry out the experimental work, a model tank of cylindrical shape of dimensions of $50 \mathrm{~cm}$ diameter and $50 \mathrm{~cm}$ height is used. Vertical load were applied to the models and the corresponding settlement were observed. The ultimate load carrying capacity of footing models was calculated and plotted by the load versus settlement graph. From the results, Improvement factor on vertical load carrying of Flat Square footing is 1.75 on loose sand. In dense sand the improvement factor of Flat Square is 1.67 . The efficiency of pyramidal shell is $75 \%$ and $66.7 \%$ on counter flat footing on loose sand and dense sand condition respectively. The settlement characteristic of triangular shell is better than other models on both loose and medium dense conditions. The load carrying capacity and efficiency of square footing having more value among other footing models for both low and medium consistency of clay. In sand the efficiency of shell is greater than in clayey soil, so the shell footings performing better way in sandy soil.
\end{abstract}

Keywords: Cohsionless soil, cohesive soil, Load carrying capacity, Flat and shell footing, improvement factor, shell efficiency, settlement factor.

\section{Introduction}

The rapid increase of human population is putting extraordinary pressure on construction land in Earth. So, we are forced to construct our structure on poor soil also. Construction of a structure on loose soil will always be a problem. This poor soil often poses design, construction and maintenance problems to Civil Engineering structures founded on them. Shell foundations are in general economic alternatives to plain shallow foundations in this situation involving heavy super structural loads to be transmitted to weaker soils, where a conventional shallow foundation undergoes excessive settlement, uses of shells in foundation leads to considerable saving in materials and in the case of shells with the straight line property and axisymmetric shells, this is achieved without much extra input of labours. The resulting economy in substantial in the developing countries of the world. Concrete as a material of construction, while the efficiency in bending lying between the most efficient in direct compression and least efficient in tension. A structure however takes its final shape only when the materials of construction are combined with labours. Shell footings can be highly labour intensive depending upon the intricacy of its geometry. This means that if we combine the aspects of material and labour.

AbdulhaHz O. Al Shenawy \& Awad A. A1-Karni [1] studied two layered system of shallow footing. They presented a detailed parametric study of the design parameters including the effect of angle of friction, the ratio of the thickness of sand layer to the footing width, the ratio of the depth of embedment to width footing, and the ratio of the clay soil cohesion to the product of the clay unit weight by the footing width. Dr. Pusadkar Sunil Shaligram [2] studied on Triangular shell footing used as a strip footing resting on two-layered sand, reinforced with geotextiles. The bottom layer is stronger than the upper layer. The geotextile layer at various levels below the footing shows increase in ultimate bearing capacity at upper layer and decrease in the settlement. It was also observed that the placement of geotextile below footing produce better load settlement characteristics when geotextile was placed. It also suggests the use of precast concrete technology construction of shell foundations. The advantage of shell footing can be better used for placing the footing on weak soil reinforced with geotextiles. Murat Ornek, Ahmet Demir, Mustafa Laman and 
Abdulazim Yildiz [3] numerically they published their results of the scale effect for circular footings on partially replaced compacted layers of clay deposit. Their results showed that the stabilization had a considerable effect on the bearing capacity of the circular footings. Also, the bearing capacity depends upon different $\mathrm{H} / \mathrm{D}$ ratio. The improved performance of the reinforced system can be described by the bearing capacity ratio ( $\mathrm{BCR})$. Based on numerical and field test results that the BCR of the partially replaced, natural clay deposits increased with an increase in the footing diameter. W.R. Azzam, A.M. Nasr [4] studied, the ultimate load capacities of shell foundations on unreinforced and reinforced sand by laboratory model tests. They conducted model test on tank of inside dimensions of $90 \mathrm{x}$ $30 \mathrm{~cm}$ in plane and $120 \mathrm{~cm}$ in depth, the wall thickness 6 $\mathrm{mm}$ is provided. The strip shell footing models were made of steel plates with constant width $(B=150 \mathrm{~mm})$ in horizontal projection, with different embedment depth, a $(a=60,75$ and $112.50 \mathrm{~mm}$ ) and $20 \mathrm{~mm}$ thickness. To satisfy the plain strain condition the transverse footing length is $29 \mathrm{~cm}$ provided. The load tests were carried out on shell footing with and without single layer of reinforcement. The tests were done at different shell embedment depth and subgrade density. The results were compared with those for flat foundations without reinforcement. Using finite element analysis (PLAXIS) the model test results were verified. Kamal Mohamed Hafez Ismail Ibrahim [5] studied that the bearing capacity of footings constructed on soft clay soil is considerably governed by soil settlement. In this study a numerical finite element analysis using Plaxis program is used to solve the problem. The axis of symmetry and the right vertical boundaries are laterally constrained. The right boundary was chosen at a distance approximately $6 \mathrm{~B}$ from the axis of symmetry while the hinged bottom boundary was established at a depth $6 \mathrm{~B}$ for vertical and lateral constrains. A significant enhancement in bearing capacity is achieved by increasing the ratio between the granular soil thickness and the footing diameter "H/B" up to four for surface foundations $(\mathrm{D} / \mathrm{B}=0)$ and up to six for deeper foundations $(\mathrm{D} / \mathrm{B}=1.0)$. The failure mechanism is characterized by punch shear failure in the granular soil and Prandtl failure in the lower soft clay soil. It is concluded that the bearing capacity of foundations on soft clay can be improved by a layer of compacted sand or gravel. The ultimate bearing capacity is directly proportional to the angle of internal friction of granular soil " $\varphi$ ", the thickness of granular layer "H", and depth of foundation " $\mathrm{D}$ ", and also it is inversely proportional to the footing diameter "B" [6]. If the granular soil changes from medium to very dense the ultimate capacity of surface footings $(\mathrm{D} / \mathrm{B}=\mathrm{O}$ and $\mathrm{H} / \mathrm{B}>2)$ increases about $67 \%$. The improvement in bearing capacity is achieved by increasing the ratio of "H/B" up to four for surface foundations $(\mathrm{D} / \mathrm{B}=0)$ and for deeper foundations the ratio will be $(\mathrm{D} / \mathrm{B}=1.0)$ [7]. Improvement in bearing capacity is dependents upon some factors such as the footings shape ratio (L/B), skirt depth ratio (DS/B), relative density of sand (ID), unit weight of sand $(\gamma)$ [8]. They showed that the reinforcement increases the bearing capacity of subgrades and also the load-displacement characteristic of the footing is modified. Nissanka Fernando, Eranga Sendanayake [9], In this paper they showed that the performance of shell type foundations with respect to ultimate and settlement characteristics is high [10]. In this study the ultimate bearing capacity increases with decrease in peak angle of shell footings. Introduction of geotextile layer at various levels below the footing increase the ultimate bearing capacity and decrease the settlement [11]. They observed that the behaviour of shell foundations in treated soil is better than that in untreated case and the cement treated soil enhances the load settlement characteristics of foundations [12]. The bearing capacity of skirted foundations on normally consolidated undrained soil was investigated using both numerical and physical modelling [13]. They studied that the ultimate load capacity of shell footing on reinforced subgrade is higher than those on unreinforced cases and the modification of load settlement curves was observed.

The flat footing consisting of three shapes such as triangular, square and hexagonal. The counter shell parts such as triangular frustum, pyramidal frustum and hexagonal frustum are fabricated in steel. These are all regular in geometry with same horizontal projected area. These models were tested on sand and clay with different conditions.

\section{Testing Materials}

Soil: The load tests were conducted in sand and clay. Sand is collected from Noyyal River bed in Tamil Nadu. And clay is collected from Government College of Technology campus in Tamil Nadu. The index properties of the sand and clay are given in table 1 and table 2 respectively.

Test Specimen: Model tests were conducted on three different flat and shell footing models made of mild steel with an equal thickness of $8 \mathrm{~mm}$. These models are Square, Triangular and Hexagonal and Pyramidal Frustum, Triangular Frustum and Hexagonal frustum are the counter shell parts respectively. These models are regular in geometry with equal horizontal projected area. The height of shell is the half of its top width $(\mathrm{D} / \mathrm{B}=0.5)$. The slanting angle of shell edges is $45^{\circ}$ to the vertical axis. The dimension of footing models as given in table 3 . Fig 1 shows the fabricated footing models.

\section{Experimental setup}

The experiments are carried out on a uni-axial loading frame available at GCT, Coimbatore having a pay load capacity of five tonnes. In sand the model tests were carried out in a cylindrical steel tank of height and diameter $50 \mathrm{~cm}$ of the tank is chosen such that the minimum free distance between the periphery of the footing and circumference of the tank should not interfere with the pressure bulb formed around the footing model due to application of load. 
Table 1. Properties of clay

\begin{tabular}{|c|c|}
\hline Properties & Values \\
\hline Gravel & $0.3 \%$ \\
\hline Sand & $31.7 \%$ \\
\hline Silt \& clay & 68 \\
\hline Differential Free Swell Index & $50 \%$ \\
\hline Optimum Moisture Content & $17.5 \%$ \\
\hline Max. Dry density & $1.63 \mathrm{~g} / \mathrm{cc}$ \\
\hline Liquid limit & $50 \%$ \\
\hline Plastic limit & $22.85 \%$ \\
\hline BIS Classification & $\mathrm{CH}$ \\
\hline
\end{tabular}

Table 2. Properties of sand

\begin{tabular}{|c|c|}
\hline Properties & Values \\
\hline Coarse Sand & $16.5 \%$ \\
\hline Medium Sand & $44.3 \%$ \\
\hline Fine Sand & $38.9 \%$ \\
\hline Silt \& clay & $0.3 \%$ \\
\hline Specific Gravity & 2.63 \\
\hline Min. Void ratio & 0.57 \\
\hline Max. Void ratio & 0.73 \\
\hline Coefficient of Uniformity & 3.44 \\
\hline ( $\mathrm{C}_{\mathrm{u}}=$ ) & \\
\hline Coefficient of Curvature & 0.754 \\
\hline BIS Classification & Poorly grade sand (SP) \\
\hline
\end{tabular}

Table 3. Dimensions of footing models

\begin{tabular}{|c|c|c|}
\hline Flat footing & Shell footing & Size (cm) \\
\hline Square & Pyramidal Frustum & 9.87 \\
\hline Triangular & Triangular Frustum & 15 \\
\hline Hexagonal & Hexagonal Frustum & 6.1 \\
\hline
\end{tabular}



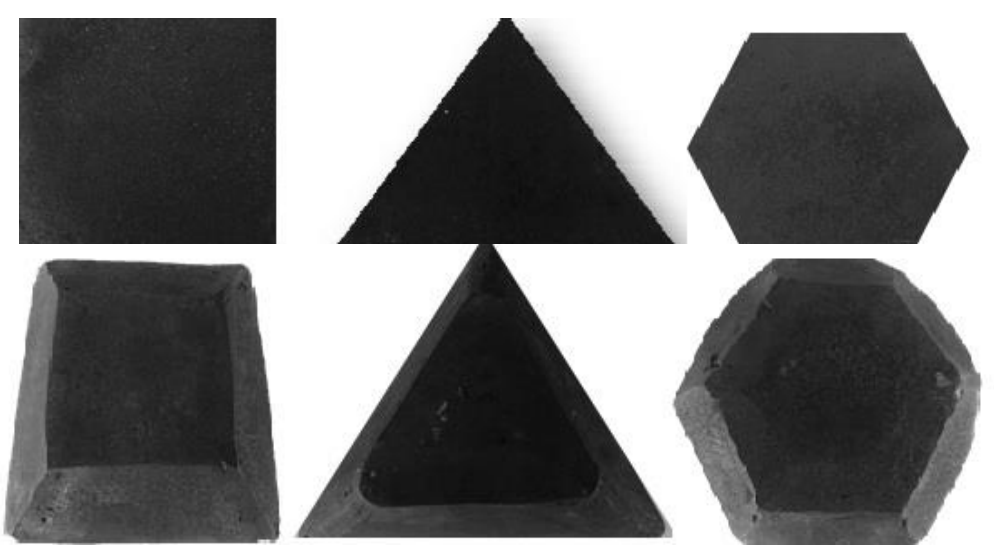

Fig 1. Flat and Shell footing models

In clay these tests were conducted in cylindrical tank of dimension $50 \mathrm{~cm}$ diameter and $35 \mathrm{~cm}$ height. The test set up comprises of the loading frame, inverted hydraulic jack, pumping unit and the test tank essentially with various footing assembly. The loading frame comprises of the reaction frame properly loaded with cement concrete cubes.

The manually operated hydraulic jack of $50 \mathrm{kN}$ capacity is clamped to it. The load from hydraulic jack is transferred to the soil through model footings. The proving ring of $5 \mathrm{kN}$ capacity is used to measure the applied load. The deflection dial gauges (2 LVDT) of $0.01 \mathrm{~mm}$ least count were placed on the models with the help of horizontal datum bars to measure the settlements of models due to loading Preparation of soil medium. In sand the tests were conducted in loose and medium dense condition. These conditions are obtained by rain fall method and another set of tests were conducted in very low $(\mathrm{w}=35 \%)$ and medium consistency $(\mathrm{w}=30 \%)$ of clay.
In sand the model test tank is placed centrally below the hydraulic jack by using plumb pop. For loose condition the sand is poured with the help of cone from just above the test tank without any vibration. After placing the sample

with required density, the soil in tank is leveled smoothly. The flat and shell footings were tested on loose sand medium. The model footing is placed centrally on the leveled soil surface.

The proving ring is placed centrally on the model footing, which is used to measure the magnitude of applied load. And the two LVDTs are placed in opposite manner on the model footing for measuring the settlement of footing. The load was applied slowly by the hydraulic jack, which is operated manually by the lever arrangement. The settlement readings were taken with respect to one division of proving ring reading. The test methodology is same for medium dense soil condition. The same procedure is adopted also in clay of low and medium consistency state. The Fig shows the model tests in sand and clay respectively.

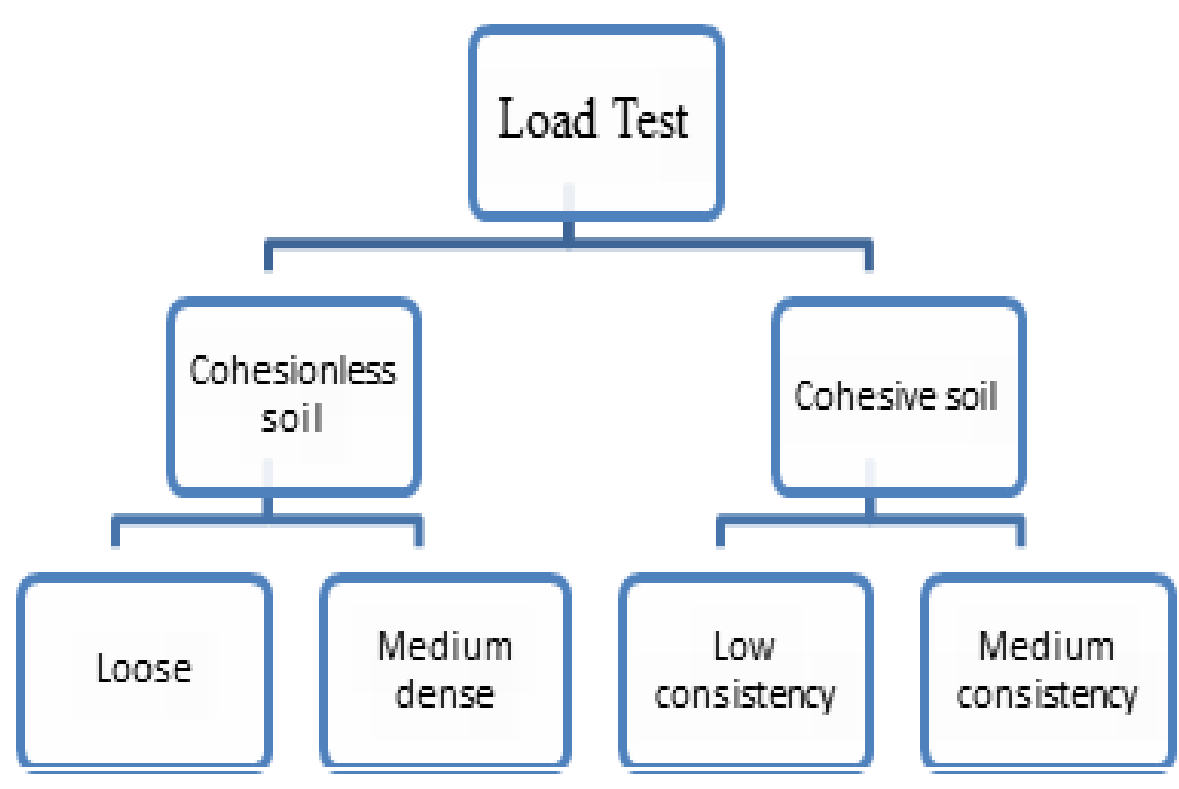




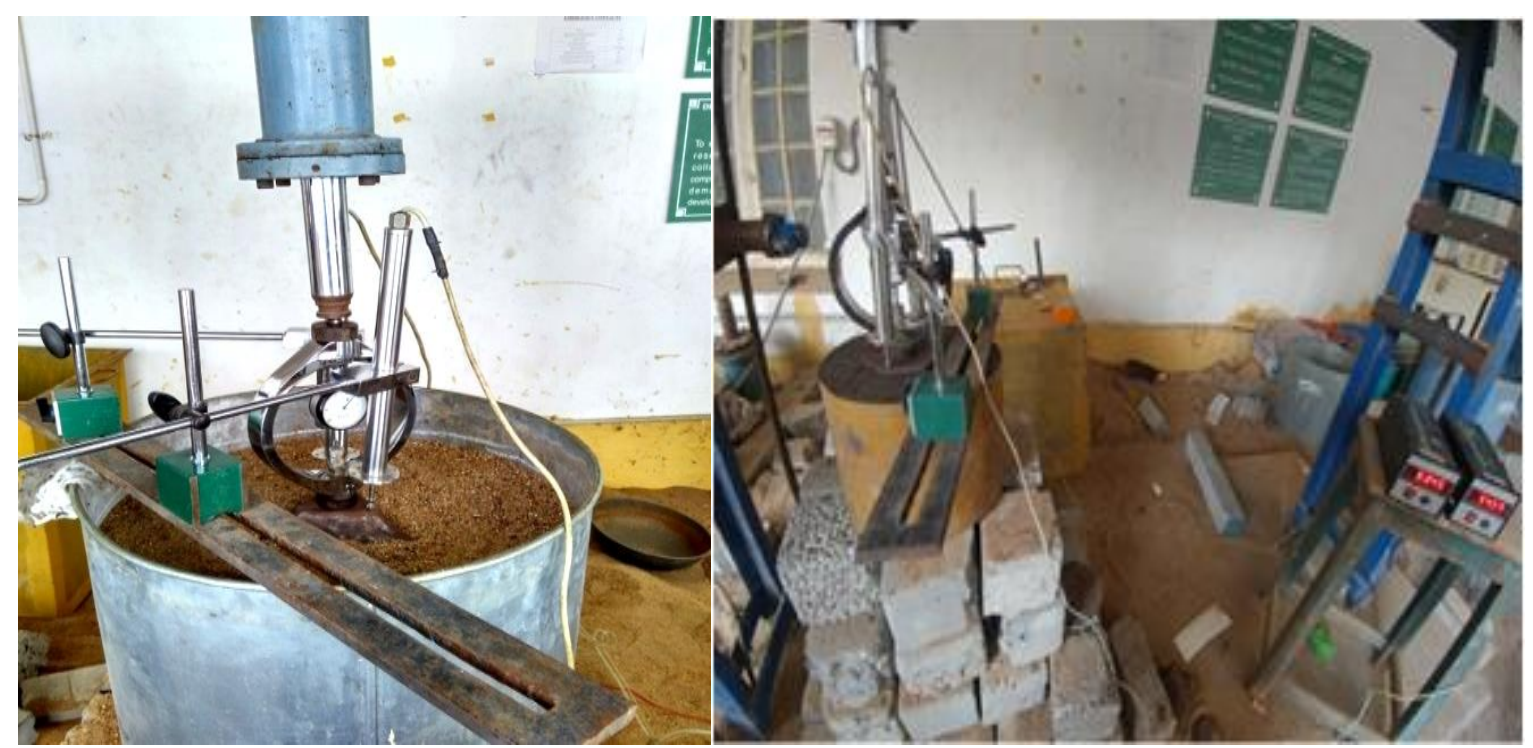

Fig 2. Test setup in sand

Fig 3. Test setup in clay

\section{Presentation of results}

The Ultimate load is calculated by initial and final tangent method for uniform curves. But in some cases there is no clear failure point so it is difficult to find out a clear failure point in the load settlement curve. To overcome this problem scientist Abbet introduced method of drawing load settlement curve. According to this method, a Log Log chart is plotted with settlement is plotted as Abscissa against corresponding pressure intensities as Ordinate. Among all
Footing the triangular shell having large internal surface area than other models. From Fig 4 to 9 clearly shows us the Ultimate load carrying capacity of triangular flat and shell footings behaves in better way than other models for both loose and medium dense soil conditions. Also the square flat and pyramidal shell is also giving its better performance than hexagonal one. From Fig 10 to 13 shows us the Ultimate load carrying capacity of square footing having more value among other models in both low and medium consistency of clay.

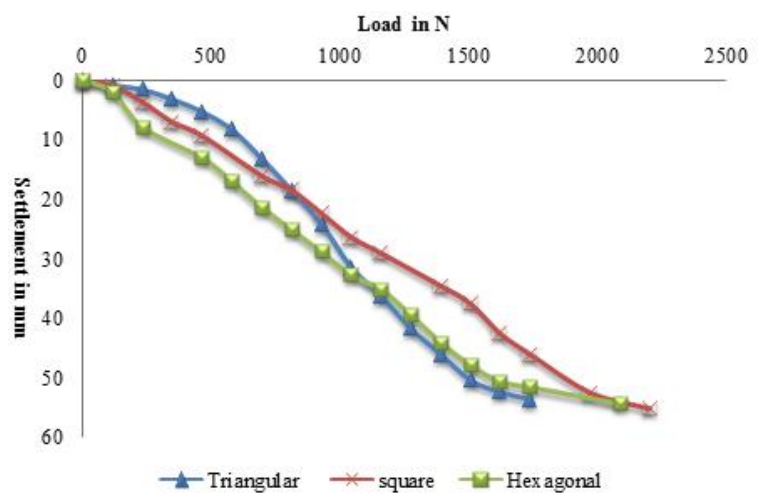

Fig 4. Load vs settlement curve for flat footings on loose sand

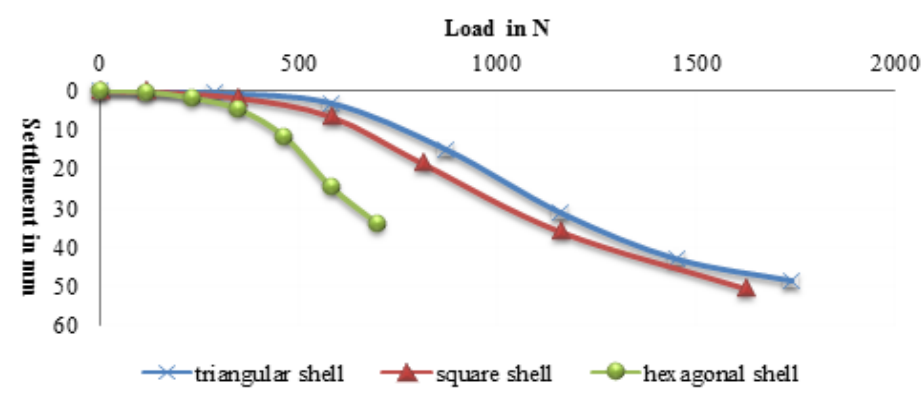

Fig 5. Load vs settlement curve for shell footings on loose sand 


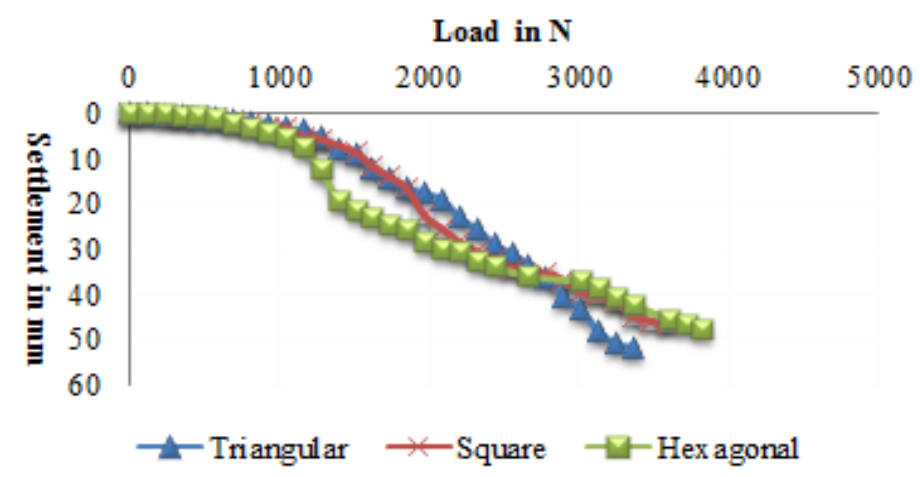

Fig 6. Load vs settlement curve for flat footing on dense sand

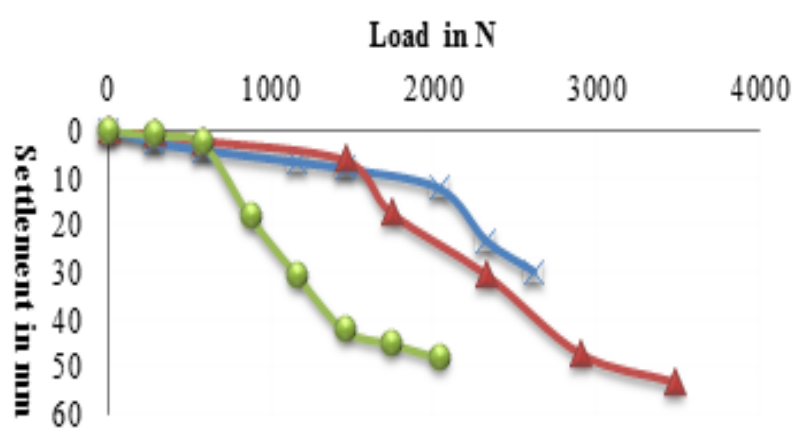

$\leftarrow$ triangular shell $\rightarrow$ square shell -0 -hex agonal shell

Fig 7. Load vs settlement curve for shell footing on dense sand

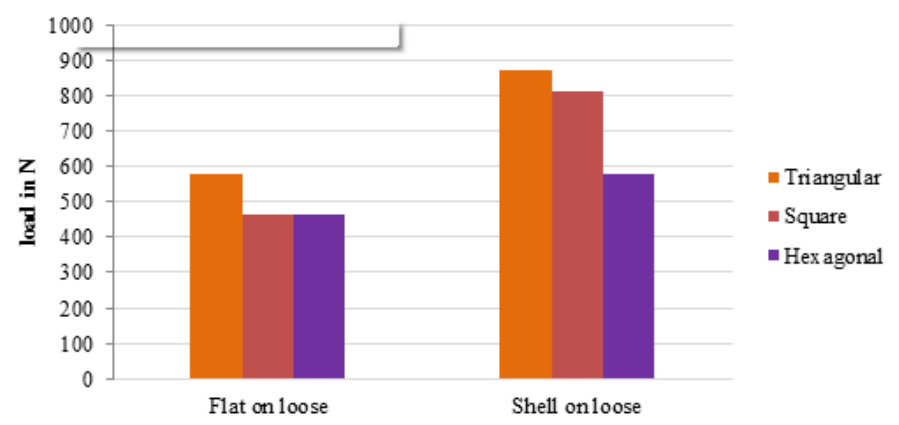

Fig 8. Comparison of load carrying capacity of flat and shell on loose sand

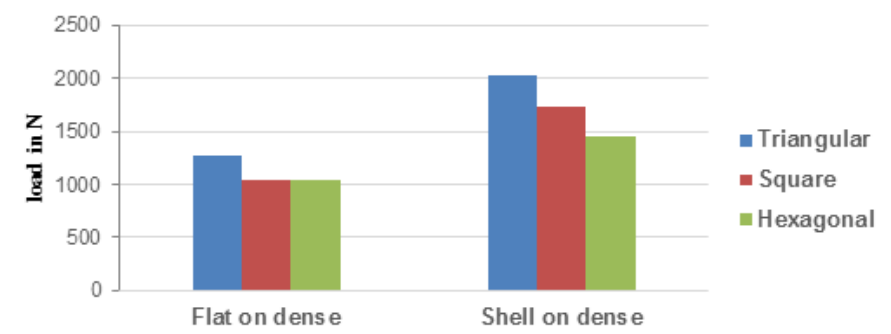

Fig 9. Comparison of load carrying capacity of flat and shell on medium dense sand 


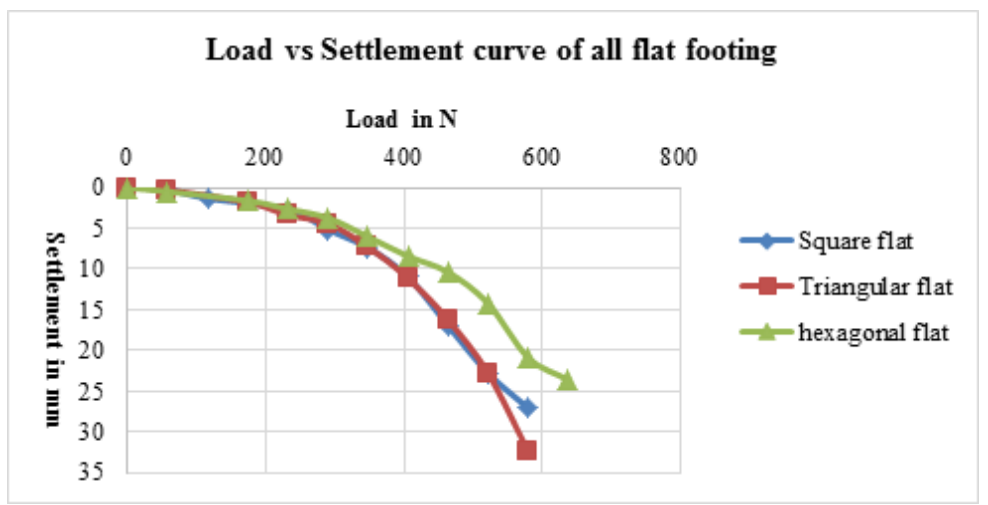

Fig 10. The Ultimate load capacity of flat footing in medium consistency of clay

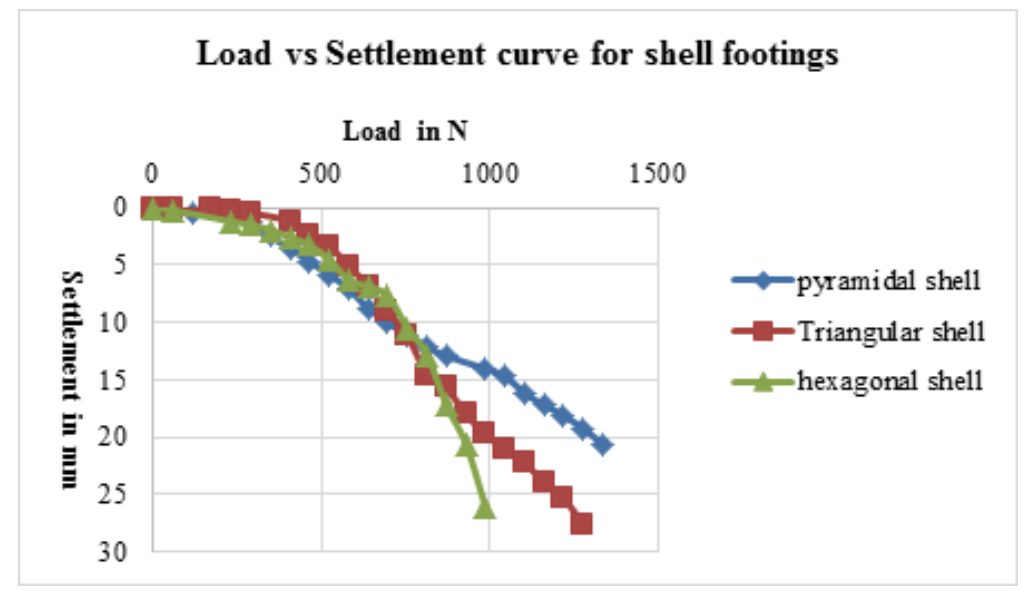

Fig 11. The Ultimate load capacity of shell footing in medium consistency of clay

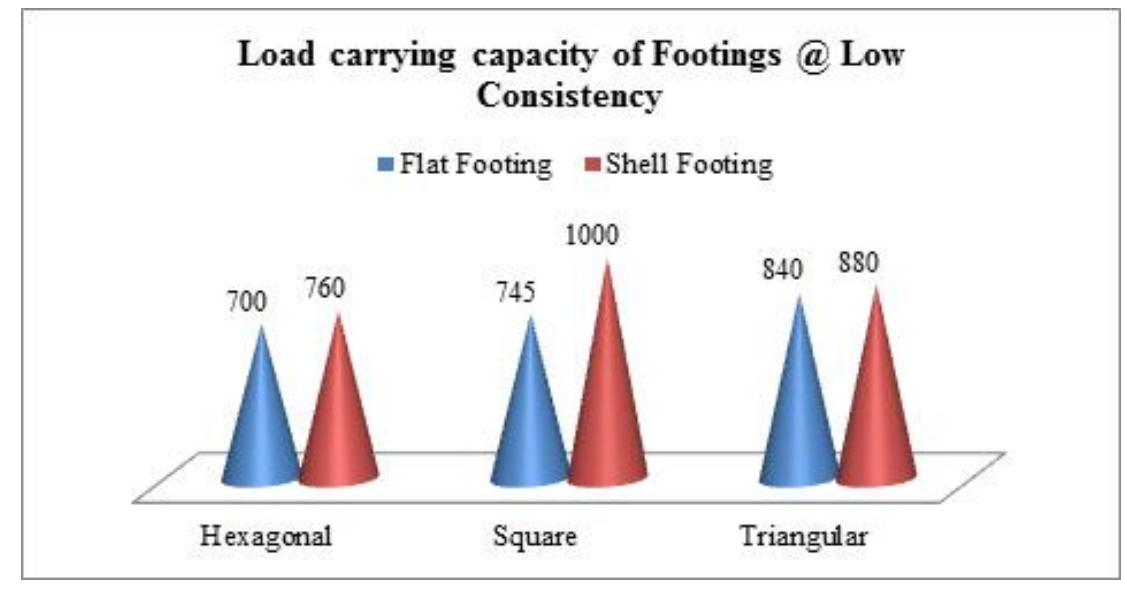

Fig 12. The Ultimate load capacity of footing in low consistency of clay 


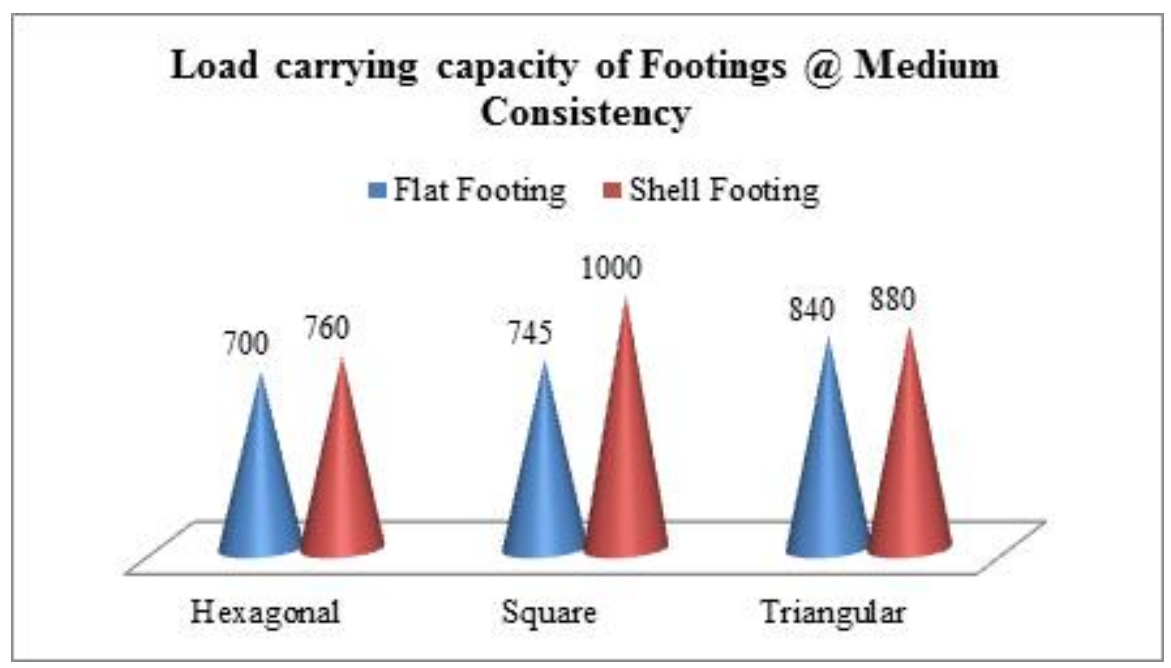

Fig 13. The Ultimate load capacity of footing in medium consistency of clay

Settlement factors characteristics. We can find which footing models behave

Different shape will behave in different manner. better than other in settlement criteria. The settlement factors The lower value of settlement indicates the better settlement

Table 4. The ultimate load and settlement with settlement factor in loose sand

\begin{tabular}{|c|c|c|c|c|}
\hline Model Type & Footing Model & Ultimate Load $(\mathbf{N})$ & Settlement $(\mathbf{m m})$ & Settlement Factor $\left(\mathbf{F}_{\mathrm{d}}\right) \mathbf{X 1 0}^{-4}$ \\
\hline \multirow{4}{*}{ Flat } & Triangular & 580 & 8.28 & 21.53 \\
\cline { 2 - 5 } & Square & 464 & 9.29 & 30.2 \\
\cline { 2 - 5 } & Hexagonal & 464 & 6.98 & 22.69 \\
\hline \multirow{3}{*}{ Shell } & Triangular Frustum & 870 & 15.02 & 20.81 \\
\cline { 2 - 5 } & Pyramidal Frustum & 812 & 15.89 & 29.71 \\
\cline { 2 - 5 } & Hexagonal Frustum & 580 & 24.43 & 46.81 \\
\hline
\end{tabular}

Table 5. The ultimate load and settlement with settlement factor in medium dense sand

\begin{tabular}{|c|c|c|c|c|}
\hline Model Type & Footing Model & Ultimate Load $(\mathbf{N})$ & Settlement $(\mathbf{M m})$ & Settlement Factor $\left(\mathbf{F}_{\mathbf{d}}\right) \mathbf{X} 10^{-4}$ \\
\hline \multirow{3}{*}{ Flat } & Triangular & 1276 & 5.21 & 6.33 \\
\cline { 2 - 5 } & Square & 1044 & 3.22 & 4.78 \\
\cline { 2 - 5 } & Hexagonal & 1044 & 5.46 & 8.1 \\
\hline \multirow{7}{*}{ Shell } & $\begin{array}{c}\text { Triangular } \\
\text { Frustum }\end{array}$ & 2030 & 12.14 & 9.27 \\
\cline { 2 - 5 } & Pyramidal Frustum & 1740 & 17.52 & 15.6 \\
\cline { 2 - 5 } & $\begin{array}{c}\text { Hexagonal } \\
\text { Frustum }\end{array}$ & 1450 & 41.955 & 44.83 \\
\hline
\end{tabular}


Table 6. Comparison of bearing capacity improvement factor

\begin{tabular}{|c|c|c|}
\hline Medium Condition & Model & $\mathbf{F}_{\mathbf{b}}$ \\
\hline \multirow{3}{*}{ Loose Sand } & Triangular & 1.5 \\
\cline { 2 - 3 } & Square & 1.75 \\
\cline { 2 - 3 } & Hexagonal & 1.25 \\
\hline \multirow{3}{*}{ Medium Dense Sand } & Triangular & 1.59 \\
\cline { 2 - 3 } & Square & 1.67 \\
\cline { 2 - 3 } & Hexagonal & 1.39 \\
\hline
\end{tabular}

(Fd) for all footing models were calculated by using the $\mathrm{F}_{\mathrm{b}}=$

following formula.

- Settlement factor (no unit), - Settlement in $\mathrm{m}$, - Unit weight of sand in $\mathrm{kN} / \mathrm{m}^{2}$

$\sim$ Horizontal projected area in $\mathrm{m}^{2}$ and - Ultimate load in $\mathrm{kN}$

From table 4 to 5 shows us the settlement factor for triangular model having less value among other models in loose and medium dense soil conditions. So the triangular model having most efficient way to transferring a load on loose soil.

- Ultimate Load Carrying Capacity of Shell in N

Ultimate Load Carrying Capacity of Flat in N Shell efficiency

The efficiency of shell footing is calculated by comparing the flat and its counter shell part. This shell efficiency is calculated for both loose and medium conditions. The shell efficiency is calculated by the following formula:

- Shell Efficiency in \%

- Ultimate Load Carrying Capacity of Shell in N

- Ultimate Load Carrying Capacity of Flat in N flat is proposed to be expressed by bearing capacity improvement factor $(\mathrm{Fb})$, which is given by,

Table 7. efficiency of shell footing on loose and medium sand

\begin{tabular}{|c|c|c|}
\hline \multirow{2}{*}{ Footing Model } & \multicolumn{2}{|c|}{ Medium Condition } \\
\cline { 2 - 3 } & $\boldsymbol{\eta}_{1}$ & $\boldsymbol{\eta}_{\text {md }}$ \\
\hline Triangular shell & 50 & 45.8 \\
\hline Square shell & 75 & 66.7 \\
\hline Hexagonal shell & 25 & 38.9 \\
\hline
\end{tabular}

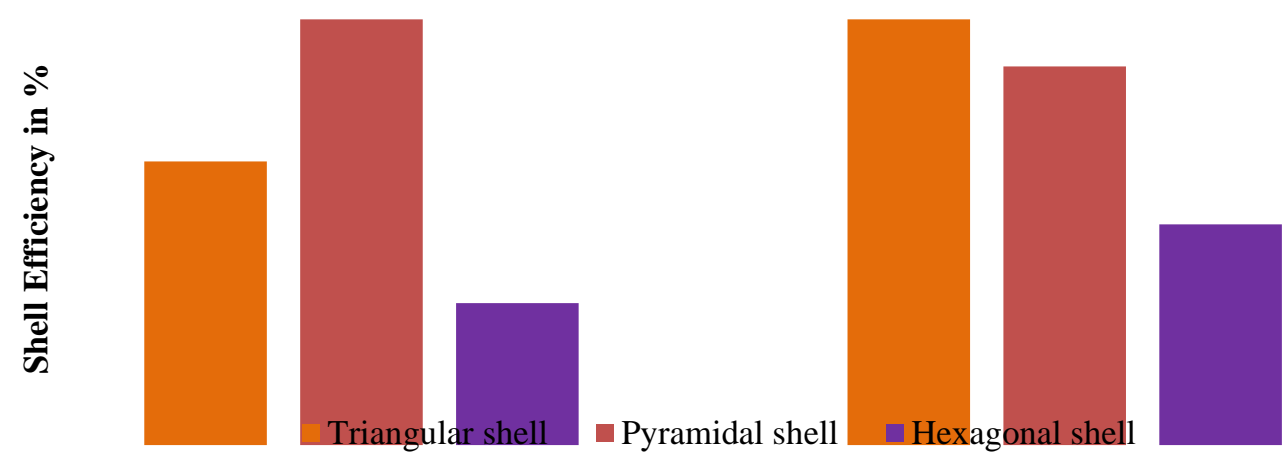

Fig 14. Efficiency of shell on loose and medium dense sand 


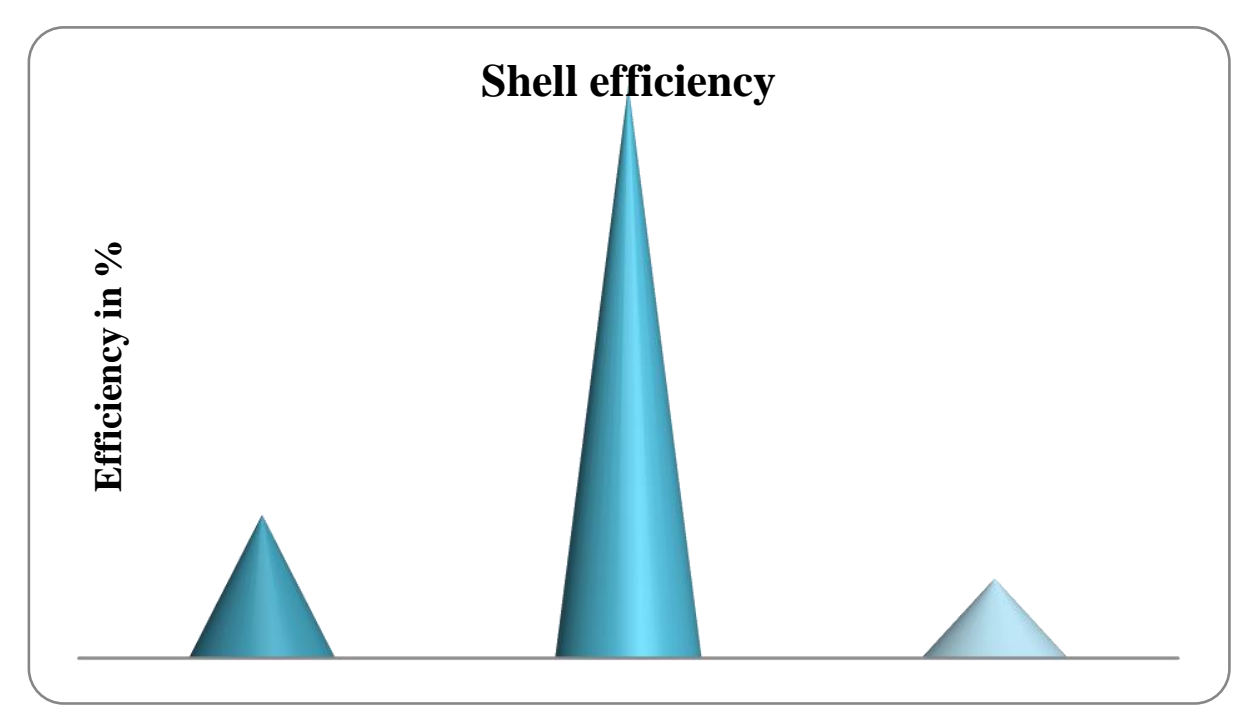

Fig 15. Efficiency of shell footings in low consistency of clay

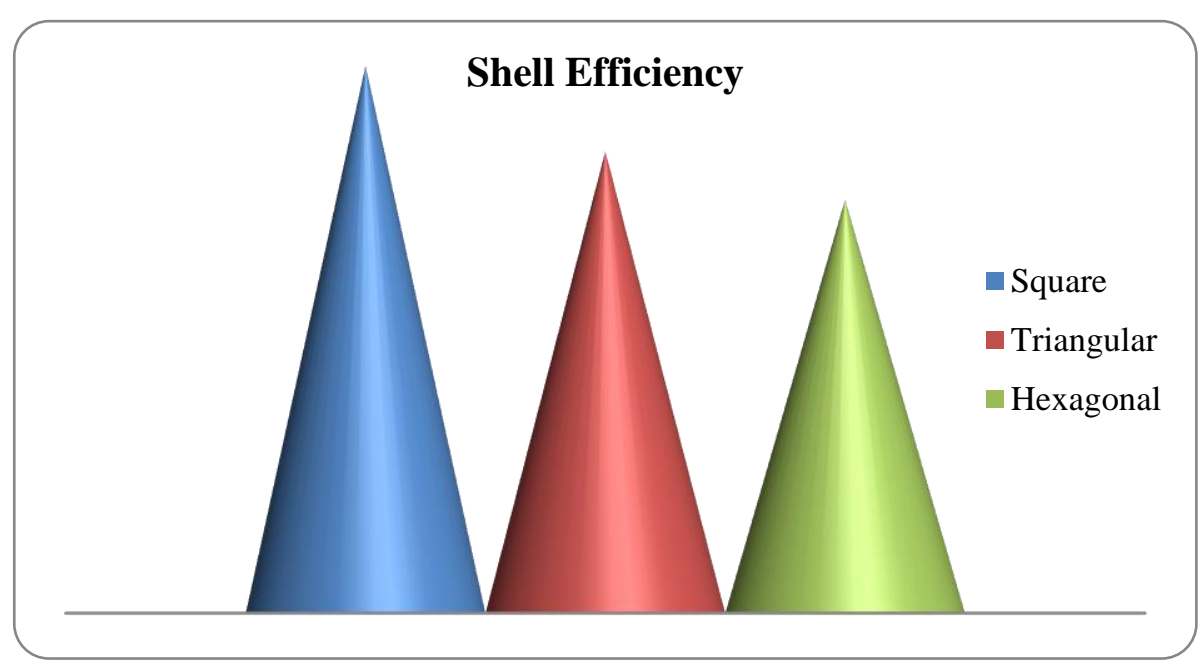

Fig 16: Efficiency of shell footings in medium consistency of clay

\section{Conclusion}

This experimental study indicates that, the characteristics of load carrying capacity and settlement factor the square shell as a better solution for constructing a structure on loose sand and low consistency of clay. If we constructing a shallow footing on loose sand or low consistency of clayey soil, the square shell is better alternative among other footings.

- Improvement factor on vertical load carrying of Pyramidal frustum is 1.75 on loose sand

- In dense sand the improvement factor of Pyramidal frustum is 1.67

- $\quad$ The efficiency of pyramidal shell is $75 \%$ and $66.7 \%$ on counter flat footing on loose and medium dense sand condition respectively.
- The settlement characteristic of triangular shell is better than other models on both loose and medium dense conditions.

- The load carrying capacity and efficiency of square footing having more value among other footing models for both low and medium consistency of clay

- In sand the efficiency of shell is greater than in clayey soil, so the shell footings performing better way in sandy soil.

\section{References}

[1] O. Abdulhahz Al Shenawy, and A. Awad Al Karni, Derivation of Bearing Capacity Equation For A Two Layered System of Weak Clay Layer Overlaid by Dense Sand Layer, Pertanika J. Sci. \& Technol. 13 (2005) 213 - 235.

[2] M.Y. Al- Aghbari, Settlement of shallow square foundation with structural skirts resting on sand, 
proceedings of the 2ND international Conference on Geotechnical and Geo environmental Engineering In Arid Lands, Riyadh, (2002) 189-194.

[3] M.Y. Al Aghbari and Y.E.A. Mohamedzein, Bearing capacity of strip foundations with structural skirts, $J$ Geotech Geoenviron, 22(2004) 43 57.

[4] J.E. Colmenares, So Ra Kang, Young Jin Shin and Jong Ho Shin, Advances in structural engineering and mechanics, (2013)3020 3040.

[5] R. Jyothi Lekshmi and P. Hashifa Hassan, Model test on bearing capacity of conical shell strip footing on reinforced clay, Int. J. Innov. Res. Sci. Eng. Technol. 4 (2015) 10290 10297.

[6] Kamal Mohamed Hafez Ismail Ibrahim, bearing capacity of circular footing resting on granular soil overlying soft clay, HBRC J. 8 July 2014

[7] Kangkan Sarma, Nayanmoni Chetia, Evaluation of Bearing Capacity for Skirted Foundations on Sand, Indian Geotechnical Conference (2017).

[8] M. A. Mahmoud, F. M. Abdrabbo, Bearing Capacity Tests on Strip Footing Resting On Reinforced Sand Subgrades, Can. Geotech. J. 26 (1989) 154-159.

[9] Nissanka Fernando, Eranga Sendanayake, Dulan Sendanayake, Nalin De Silva, The experimental investigation of failure mechanism and bearing capacity of different types of shallow foundations, Civil Engineering Research For Industry - (2011).

[10] Pusadkar, Sunil Shaligram, Behavior of Triangular Shell Strip Footing on Geo reinforced Layered Sand, Int J Adv Sci Eng Inf Technol, 2(2011).

[11] S. K. Singh, Kangujam Monika, Load Carrying Capacity of Shell Foundations on Untreated and Treated Soil, Indian Geotechnical Conference (2016).

[12] G. Yun, And M.F. Bransby, The Undrained Vertical Bearing of Skirted Foundations, Japan. Geotech. Soci. 47(2007) 493 505.

[13] W.R. Azzam , A.M. Nasr, Bearing Capacity Of Shell Strip Footing on Reinforced Sand, J. Adv. Res. Cairo University, 2014

\section{About The License}

(C) 2019 The Authors. This work is licensed under a Creative Commons Attribution 4.0 International License which permits unrestricted use, provided the original author and source are credited. 